\title{
Meniere Disease: A Case Report
}

\section{Edfina Rahmarini ${ }^{*}$, Hanik Badriyah Hidayati²}

\author{
${ }^{1}$ Resident of Neurology Medical Faculty Airlangga University \\ Dr. Soetomo General Hospital Surabaya \\ ${ }^{2}$ Staff of Neurotology at Neurology Department \\ Dr. Soetomo General Hospital Surabaya
}

\section{*Corresponding author details: Edfina; edfinarahmarinidr@gmail.com}

\begin{abstract}
Background: Meniere's disease is a clinical disorder defined as the idiopathic syndrome of endolymphatic hydrops. Meniere's disease has a prevalence of about 200 cases per 100,000 people in the United States. Prevalence increases linearly with increasing age, especially over 60 years. Men and women are estimated to be proportional in the number of cases. The etiology of Meniere's disease is currently known to be caused by intrinsic factors and extrinsic factors. Symptoms of Meniere's disease include recurrent spontaneous episodic vertigo, fluctuating hearing loss, ear fullness, and tinnitus. Treatment of Meniere's disease can be divided into pharmacological therapy and non-pharmacological therapy. In some cases, complaints can be reduced to 8090 percent.

Case Report: A woman, aged 65 years, complained of constant ringing in her right ear, feeling full and accompanied by decreased hearing in the right ear, spinning dizziness that is not related to changing position, especially when she is tired, ringing in the ear, a feeling of fullness in the ear since 3 months ago. Head MRI results were normal. The patient was treated with HCT $1 \times 50 \mathrm{mg}$, prednisone $1 \times 80 \mathrm{mg}$ for 7 days, KSR 3x1 tablet, betahistine 2x24 mg. Patients experience improvement in complaints even though the complaints do not disappear completely

Conclusion: The diagnosis of Meniere's disease is established by clinical symptoms, namely recurrent spontaneous episodic vertigo, fluctuating hearing loss, ear fullness, and tinnitus. Appropriate therapy in Meniere's disease can reduce complaints and improve the patient's quality of life.
\end{abstract}

Keywords: Meniere disease; vertigo; tinnitus; ear full sensation; hearing loss

\section{INTRODUCTION}

Meniere's disease is a chronic disorder of the inner ear, which is not fatal but interferes with quality of life $(1,2)$. Meniere disease has a prevalence of about 200 cases per 100,000 people in the United States and in other states less than $0.2 \%$ of the population has a case of Meniere disease $(1,3)$. Prevalence increases linearly with increasing age, especially over 60 years $(3,4)$. Men and women are estimated to be proportional in the number of cases $(3,4)$. Until now there is no therapy that is able to cure this disease completely, but proper therapy and treatment need to be known to be able to improve the quality of life of patients (11-17).

According to the guidelines of the American Academy of Otolaryngology-Head and Neck Surgery (AAO-HNS), Meniere's disease is characterized by 4 symptoms, namely:

(1) Vertigo: sensation of spinning, episodic, mild to severe, rotational, with a duration of at least 20 minutes per attack episode, never more than 24 hours.

(2) Hearing decline: fluctuating, low-frequency sensory deafness, which worsens during an attack, and may become progressively worse over time.

(3) Tinnitus: typical low-pitched ringing or roaring noise in the ears

(4) A feeling of fullness in the ear
$(2,7,17,18)$. The underlying pathophysiological condition in Meniere's disease is endolymphatic hydrops which is demonstrated by a definite diagnosis only by post mortem (histopathologically) biopsy of the temporalis $(1,19,20)$. For clinical purposes (treatment and reporting) the presence of endolymphatic hydrops can be inferred during life by the presence of the following signs or symptoms such as recurrent spontaneous episodic vertigo, fluctuating hearing loss, ear fullness, and tinnitus $(5,8,9)$. Meniere's disease was first discovered in 1861 by Prosper Meniere and published his article as a case series in the Paris medical journal entitled Apoplectic Cerebral Congestion, which is known as a brain disorder $(5,17,21)$. At that time, Prosper Meniere explained the pathological abnormalities that were highlighted in published articles in the form of peripheral organ disorders characterized by episodic vertigo accompanied by fluctuating hearing loss (2).

The etiology of Meniere's disease is currently known to be caused by intrinsic factors (genetic disorders, anatomical abnormalities, metabolic factors, endocrine disorders, autoimmune, and vascular disorders) as well as extrinsic factors (allergies, trauma, and viral infections) $(20,22,23)$. Currently, MRI can be used as a diagnostic tool to determine the etiology of Meniere's disease $(24,25)$. Pathophysiology Meniere's disease occurs due to endolymphatic hydrops in the inner ear causing damage to ganglion cells (22). 
In addition, increased ear pressure causes irritation of the saccule, utricle which causes additional symptoms such as dizziness, arousal and disequilibrium (13). The highest pressure is found at the apex of the cochlea, which has receptor neurons that are sensitive to low-frequency sounds, so this area is often disturbed $(8,22)$. Increased pressure in the endolymph is fluctuating so that Meniere's attacks will also fluctuate (2). An increase in the volume of the endolymph causes the Reisner membrane to rupture so that the perilymph and endolymph fluids will fuse while there is a difference in fluid concentration between the perilymph (Na 1mM K $150 \mathrm{mM}$ ) and endolymph (Na 140 mM K 7mM) (2). The mixing of perilymph and endolymph fluid causes neuron receptors in the cochlea and vestibular system to be submerged so that they stop working and eventually their function is temporarily impaired. This results in impaired balance and hearing function (2).

The current therapy for Meniere's disease based on neurotology and neuroophthalmological study groups is classified into pharmacological and non-pharmacological therapies (26). Pharmacological therapy includes diuretic hydrochlorothiazide and acetazolamide at a dose of $50 \mathrm{mg}$ per day, corticosteroid prednisone $80 \mathrm{mg}$ once a day for up to 7 days then tapering off, antivertigo betahistine at a dose of $48 \mathrm{mg}$ per 24 hours, the patient can be given potassium orally to prevent hypokalemia due to diuretic administration, as well as anti-histamine $(9,21)$. While non-pharmacological therapy that can be given is a lowsalt diet of 1.5-2 grams per day, a high-potassium diet, hydration, non-destructive intervention therapy with intratympanic steroid injection, endolymphatic sac mastoid decompression and or shunt, destructive therapy with intratympanic injection of gentamicin (chemical labyrinthectomy)., as well as adaptive and rehabilitative therapy $(9,21)$.

In some cases of Meniere's disease if treated seriously can reduce symptoms up to 80-90 percent, however, based on previous studies there have never been reported cases that fully recovered $(9,27)$. In the following, we will present a case report about Meniere's disease with a diagnostic in the form of MRI of the head with contrast and audiology, the patient experienced improvement in complaints after being given therapy.

\section{CASE REPORT}

A woman, Mrs. A, aged 65 years in the neurology department, complained of constant ringing in her right ear, feeling full and accompanied by decreased hearing since approximately 3 months before her visit to the RSDS neurology clinic. The patient also complains of occasional spinning dizziness which is not related to a change in position.
The spinning dizziness appears unpredictable and sometimes suddenly appears especially when the patient is tired. Complaints of spinning dizziness appeared since 3 months ago along with symptoms of ringing in the ears, fullness in the ears and hearing loss.

On physical examination, patient was found to be hypcusis in the right ear, on the Rinne test, abnormalities were found in the right ear, on Weber's examination, lateralization was found to the left. Patient's audiological examination revealed that the sensorineural writing of the right ear was found. Other cranial nerve examinations were within normal limits. And other neurological physical examination found no abnormalities. Based on the results of head MRI with contrast, there were no abnormalities.

Patient was treated with hydrochlorothiazide $50 \mathrm{mg}$ 1-0-0 once a day and prednisone $1 \times 80 \mathrm{mg}$ once a day for up to 7 days and then tapering off was given, given neurotropic vitamin B1 B6 B12 2x1 and betahistine mesylate 2x24 mg if severe dizziness was found.

Patient was evaluated and in the third week after treatment the patient found that the ear fullness was reduced, there was still occasional spinning dizziness, the ringing in the ears was slightly reduced but the hearing loss had not been improved.

\section{DISCUSSION}

Based on the 1995 AAO-HNS criteria, there were 4 symptoms of Meniere's disease, namely:

(1) Vertigo (sensation of spinning, mild to severe episodic, rotational, with a duration of at least 20 minutes each attack episode never more than 24 hours).

(2) Hearing decline: fluctuating, low-frequency sensory deafness, which worsens during the attack, and the longer the bias gets worse.

(3) Tinnitus (low tone ringing or roaring noise in the ears).

(4) A feeling of fullness in the ear $(2,7,17,18)$. We got the four symptoms above in the patient, since 3 months before the patient came for treatment to the neurologist.

The audiological examination showed that the right ear sensorineural results showed that the diagnosis of definite Meniere's disease had been established based on the 1995 AAO-HNS criteria, namely:

(1) At least 2 definitive vertigo episodes of at least 20 minutes duration

(2) Audiometry: write sensory at least 1 time

(3) Tinnitus or a feeling of fullness in the ear that hurts

(4) Other causes of vertigo can be ruled out $(2,7,17,18)$.

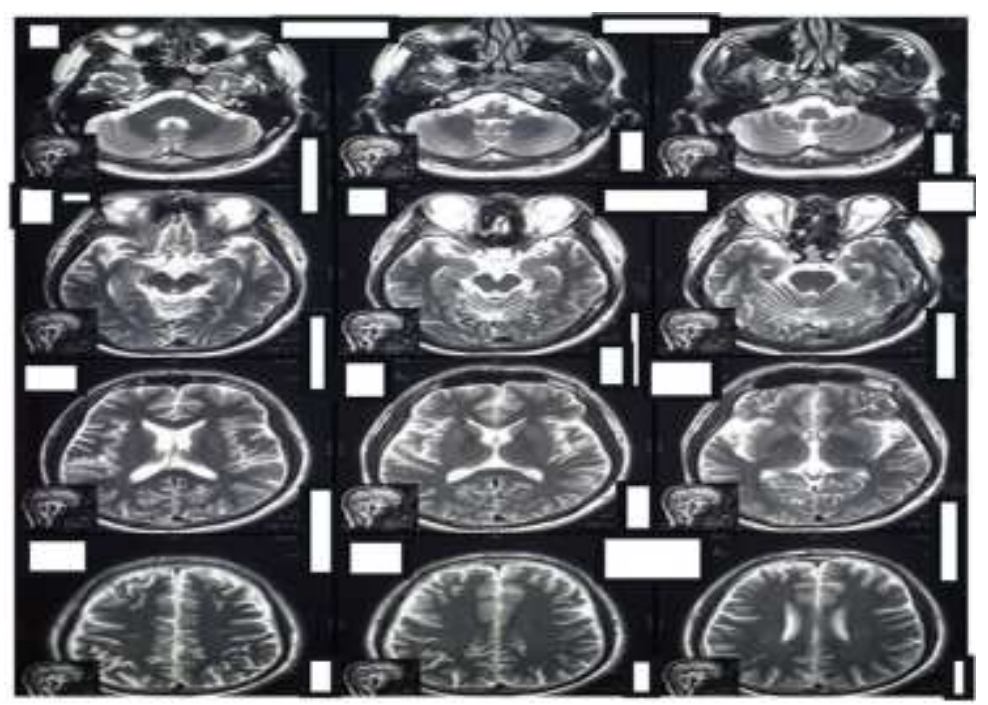

FIGURE 1: MRI T2 Sequent patient diagnosed Meniere Disease 
The results of the head MRI examination with contrast of the patient showed no abnormalities, but this did not rule out the diagnosis of Meniere's disease. The patient was given therapy in the form of Hydrochlorothiazide (HCT $1 \times 50 \mathrm{mg}$ ) and antivertigo betahistine mesylate $2 \times 24 \mathrm{mg}$ the patient was also given prednisone tablet $1 \times 80 \mathrm{mg}$ for 7 days and then tapered off. Treatment evaluation was carried out every 1-2 weeks to 1 month after treatment, the patient's complaints of spinning dizziness and ringing in the ears were less than before but had not disappeared completely while hearing loss in the right ear had not improved. Currently, we are still evaluating the patient and the therapy that has been given

\section{CONCLUSSION}

Meniere's disease is characterized by clinical symptoms such as episodic vertigo, tinnitus, ear fullness, and hearing loss (sensorineural deafness) (8). Meniere's disease can be caused by intrinsic factors (genetic abnormalities, anatomic abnormalities, metabolic factors, endocrine disorders, autoimmune, and vascular disorders) or extrinsic (allergies, trauma, or viral infections) (28). Pathophysiology Meniere's disease is caused by hydrops endolymph which causes damage to receptor neurons in the inner ear (29).

The current therapy for Meniere's disease is divided into pharmacological and non-pharmacological therapies. Currently, if Meniere's disease is treated seriously, it can reduce complaints by up to 80-90 percent although it cannot eliminate or completely cure symptoms, but this means improving the patient's quality of life (26).

\section{REFERENCES}

[1] Basura G], Adams ME, Monfared A, Schwartz SR, Antonelli PJ, Burkard R, et al. Clinical Practice Guideline: Ménière's Disease Executive Summary. Otolaryngol Head Neck Surg (United States). 2020;162(4):415-34.

[2] Magnan J, Özgirgin ON, Trabalzini F, Lacour M, Escamez AL, Magnusson M, et al. European position statement on diagnosis, and treatment of meniere's disease. J Int Adv Otol. 2018;14(2):317-21.

[3] Alexander TH, Harris JP. Current Epidemiology of Meniere's Syndrome. Otolaryngol Clin North Am [Internet]. 2010;43(5):965-70. Available from: http://dx.doi.org/10.1016/j.otc.2010.05.001

[4] Segal S, Eviatar E, Berenholz L, Kessler A, Shlamkovitch N. Is there a relation between acoustic trauma or noise-induced hearing loss and a subsequent appearance of Ménière's Disease? An epidemiologic study of 17,245 cases and a review of the literature. Otol Neurotol. 2003;24(3):387-91.

[5] Tassinari M, Mandrioli D, Gaggioli N, Roberti Di Sarsina P. Ménière's disease treatment: A patientcentered systematic review. Audiol Neurotol. 2015;20(3):153-65.

[6] Phillips JS, Westerberg B. Intratympanic steroids for Ménière's disease or syndrome. Cochrane Database Syst Rev. 2011;(7).

[7] Lopez-Escamez JA, Carey J, Chung WH, Goebel JA Magnusson $\mathrm{M}$, Mandalà $\mathrm{M}$, et al. Criterios diagnósticos de enfermedad de Menière: Documento de consenso de la Bárány Society, la Japan Society for Equilibrium Research, la European Academy of Otology and Neurotology (EAONO), la American Academy of Otolaryngology-Head and Neck Surgery (AA. Acta Otorrinolaringol Esp [Internet]. 2016;67(1):1-7. Available from:

http://dx.doi.org/10.1016/j.otorri.2015.05.005
[8] Espinosa-Sanchez JM, Lopez-Escamez JA. Menière's disease [Internet]. 1st ed. Vol. 137, Handbook of Clinical Neurology. Elsevier B.V.; 2016. 257-277 p. Available from: http://dx.doi.org/10.1016/B978-0444-63437-5.00019-4

[9] Bogaz EA, Freitas A, Ribeiro DK, Freitas S. Meniere' s Disease Treatment.

[10] Patel M, Agarwal K, Arshad Q, Hariri M, Rea P, Seemungal BM, et al. Intratympanic methylprednisolone versus gentamicin in patients with unilateral Ménière's disease: a randomised, double-blind, comparative effectiveness trial. Lancet [Internet]. 2016;388(10061):2753-62. Available from:http://dx.doi.org/10.1016/S01406736(16)31461-1

[11] Burgess A, Kundu S. Diuretics for Ménière's disease or syndrome. Cochrane Database Syst Rev. 2009;(4).

[12] Pullens B, van Benthem PP. Intratympanic gentamicin for Meniere's disease or syndrome. Cochrane database System

Rev. 2011;(3):CD0082(3):CD008234.

[13] Van Esch BF, Van Der Zaag-Loonen HJ, Bruintjes TD, Van Benthem PPG. Interventions for Menière's disease: Protocol for an umbrella systematic review and a network meta-analysis. BMJ Open. 2016;6(6):6-8.

[14] Syed MI, Ilan O, Nassar J, Rutka JA. Intratympanic therapy in Meniere's syndrome or disease: Up to date evidence for clinical practice. Clin Otolaryngol. 2015;40(6):682-90.

[15] Pullens B, Verschuur HP, Van Benthem PP. Surgery for Ménière's disease. Cochrane Database Syst Rev. 2013;2013(2).

[16] van Sonsbeek S, Pullens B, van Benthem PP. Positive pressure therapy for Ménière's disease or syndrome. Cochrane Database Syst Rev. 2015;2015(3).

[17] Devaiah AK, Ator GA. Clinical indicators useful in predicting response to the medical management of Meniere's disease. Laryngoscope. 2000;110(11):1861-5.

[18] Casani AP, Guidetti G, Schoenhuber R. Report from a consensus conference on the treatment of ménière's disease with betahistine: Rationale, methodology and results. Acta Otorhinolaryngol Ital. 2019;38(5):460-7.

[19] Devantier L, Djurhuus BD, Hougaard DD, Händel MN, Guldfred FLA, Schmidt JH, et al. Intratympanic Steroid for Menière's Disease: A Systematic Review. Otol Neurotol. 2019;40(6):806-12.

[20] Basura G], Adams ME, Monfared A, Schwartz SR, Antonelli PJ, Burkard R, et al. Clinical Practice Guideline: Ménière's Disease. Otolaryngol - Head Neck Surg (United States). 2020;162(2_suppl):S1-55.

[21] Nevoux J, Barbara M, Dornhoffer J, Gibson W, Kitahara T, Darrouzet V. International consensus (ICON) on treatment of Ménière's disease. Eur Ann Otorhinolaryngol Head Neck Dis [Internet]. 2018;135(1): S29-32. Available from: http://dx.doi.org/10.1016/j.anorl.2017.12.006 
[22] Chiarella G, Petrolo C, Cassandro E. The Genetics of Meniere' s Disease. Appl Clin Genet. 2015;8(8):9-17.

[23] Schwaber MK. Transtympanic gentamicin perfusion for the treatment of Meniere's disease. Otolaryngol Clin North Am. 2002;35(2):287-95.

[24] Nakashima T, Pyykkö I, Arroll MA, Casselbrant ML, Foster CA, Manzoor NF, et al. Meniere's disease. Nat Rev Dis Prim [Internet]. 2016;2(May):1-19. Available from: http://dx.doi.org/10.1038/nrdp.2016.28

[25] Vassiliou A, Vlastarakos P, Maragoudakis P, Candiloros D, Nikolopoulos T. Meniere's disease: Still a mystery disease with difficult differential diagnosis. Ann Indian Acad Neurol. 2011;14(1):12-8.
[26] Da Cruz M. Ménière's disease: A stepwise approach. Med Today. 2014;15(3):18-26.

[27] Bogaz EA, Silva AFC da, Ribeiro DK, Freitas G dos S. Meniere's Disease Treatment. Up to Date Meniere's Dis. 2017;(October).

[28] Da Costa SS, De Sousa LCA, De Toledo Piza MR Meniere's disease: Overview, epidemiology, and natural history. Otolaryngol Clin North Am. 2002;35(3):455-95.

[29] Wright T. Ear, nose, and throat disorders Menière ' s disease Search date July 2014 THIAZIDE DIURETIC ) TO PREVENT ATTACKS AND Ear, nose, and throat disorders Menière's disease. 2015;(July 2014):1-18. 